\title{
FINANCIAL AUDIT IN AN ARENA CONTEXT. AN ANALYSIS AT THE MESO-LEVEL
}

\author{
Țurlea Eugeniu ${ }^{l}$ \\ Ştefănescu Aurelia ${ }^{2}$ \\ Mihaela Mocanu ${ }^{3}$
}

\begin{abstract}
Research has generally focused either on the auditors' decision-making process at micro-level or on the financial audit environment at macro-level. The present paper's contribution to knowledge consists in filling in this research gap by performing an analysis of the financial audit environment at meso-level and by pointing out the significance of strategic thinking in managing financial audit companies. The research method consists in applying to the financial audit field the so-called "arena concept", a metaphor that describes in a symbolic manner the location of actions which influence collective decisions or policies. The main strength of the applied model is that it structures and represents participants, communication, patterns of interaction, and decisionmaking processes. The authors conclude that there is a variety of interactions in the financial audit field and that each group of participants may change the business dynamics.
\end{abstract}

Key words: financial audit, arena, interactions, strategic thinking

JEL codes: $M 42$

\section{Introduction}

Financial audit is a knowledge-intensive service, an activity taking place in a strictly regulated and a highly litigious environment, where innovation and entrepreneurship do not seem to fit in. Financial auditors are compelled to display professional behavior in all circumstances and to put the interest of the public above all other interests. They must observe numerous regulations, including ethical provisions (e.g. IFAC, Code of Ethics for Professional Accountants), so that their activity is rarely seen as a business open to innovation. In fact, few researchers (e.g. Turlea and Mocanu, 2010) considered that financial audit is a business like many others and offered a strategic perspective on this field. In most of the existing literature, there is a strict differentiation of the status of financial audit, which is considered rather a profession than a business (Cheffers and Pakaluk, 2007).

Few researchers analysed financial audit at meso-level or from a strategic point of view. Instead, research focused on the client-auditor relationship from a game-theoretical perspective, by analyzing the interaction between auditor and auditee and their alternative behaviors (Nguyen, 2005; Coate et al., 2002). The issue of an audit report signaling financial difficulties of the auditee has also been investigated from a game-theoretical perspective, in order to identify bias in the auditor's decision making (Tucker et al., 2003). Some have tried to offer a strategic perspective on this field by applying innovative models (such as the co-opetition model) to financial audit (T,urlea and Mocanu, 2010). Nevertheless, few have analyzed the interactions in the audit environment at meso-level.

\footnotetext{
${ }^{1}$ Professor PhD Academy of Economic Studies Bucharest, Piața Romană nr. 6, Sector 1, Bucureşti, eturlea@yahoo.com

${ }^{2}$ Professor PhD, Academy of Economic Studies Bucharest, Piaţa Romană 6, Sector 1, Bucureşti, stefanescu.aura@gmail.com

${ }^{3}$ PhD Student, Academy of Economic Studies Bucharest, Piața Romană 6, Sector 1, Bucureşti, mihaela.g.mocanu@gmail.com
} 
The present paper fills in this research gap, by applying the arena concept to financial audit. This analysis, original in itself, provides arguments for strategic thinking in managing an audit company. The remainder of this paper is structured as follows. First, a short review of the relevant literature in the field is carried out. Then, a brief overview of the research methodology is provided to the reader. Then, the arena concept is presented. Next, the concept is applied to financial audit, by identifying the main actors in the arena, their objectives, their influence and interactions. The last section includes discussions and conclusions on the chosen topic.

\section{Literature review}

In its evolution until present days, the financial audit profession experienced difficult times. The accounting scandals from the beginning of the twenty-first century brought financial auditors under critique. There is an extensive body of research that intensively debated on those events (e.g. Carnegie, Napier 2010; Cooper, Neu 2006; McMillan 2004), with significant consequences for the profession in terms of relevant regulatory framework. Additionally, due to the current so-called economic and financial "crisis" which threatens to spread internationally, auditors again came under heavy critique. Headlines such as "Where were the auditors?" are a frequent response of newspapers to recent financial collapses of companies, as if auditors held the responsibility for these failures. This state of facts also stimulated debates about current auditing practices (e.g. Sikka 2009; Humphrey et al. 2009).

Additionally, contemporary social trends like globalization, terrorism, the knowledge society and the postmodern rejection of authority and deference towards the established professions are also taken into consideration by the literature in the financial audit field (see as example McPhail and Walters, 2009). Some (but few) researchers (see Țurlea and Mocanu, 2010) also aimed at offering a strategic perspective in financial audit. Research generally focused on the clientauditor relationship analyzed from a game-theoretical perspective, by investigating the interaction between auditor and auditee and their alternative behaviors (Nguyen, 2005; Coate et al., 2002). The issue of an audit report signaling financial difficulties of the auditee has also been researched from a game-theoretical perspective, in order to identify bias in the auditor's decision making (Tucker et al. 2003). Nevertheless, the literature on financial audit lacks on analyses of the audit environment at meso-level. The present paper contributes to filling in this knowledge gap. An analysis of the interactions within the audit environment is considered by the authors as essential for a better understanding of the financial auditing role, given the current world-wide context (economic turmoil, globalization, knowledge society, postmodern rejection of authority and deference towards the established professions etc.).

\section{Research methodology}

The research methodology mainly consists in deductive research mechanisms, namely in applying the so-called "arena concept" (the general case) to the financial audit field (the particular case). Firstly, the arena concept is explained. In brief, it is a metaphor that describes in a symbolic manner the location of actions which influence collective decisions or policies. Then, the authors investigate the financial audit environment and identify the main actors within the particular case of the financial auditing arena (companies, rules enforcers, issue amplifiers, political institutions, main categories of stakeholders, and members of the general public). Subsequently, the resources, objectives and the amount of influence of each actor are identified and the interdependencies among these actors in the financial audit arena are analyzed. Last but not least, some conclusions based on the performed analysis are drawn, respectively that there is a variety of interactions in the financial audit field and that each group of participants may change the business dynamics. 


\section{The arena concept}

"An arena is a metaphor to describe the symbolic location of actions that influence collective decisions or policies. An arena attempts to explain the process of policy formulation and enforcement in a specific context" (Georgakopoulos and Thomson, 2008, pp. 1120). The level of analysis within the arena concept is the meso-level of society rather than the individual (microlevel) or societal behavior as a whole (macro-level). Moreover, relevant in the arena are the actions of individuals or social groups that intend to influence collective decisions or policies. An actor succeeds or fails depending on the amount of influence he has been able to exert on the resulting decision or policy (Jaeger et al., 2001, pp. 176). In order to pursue their objectives, different actors use social resources such as money, power, social influence and evidence. The final objectives of an actor may range from resource accumulation to the resources themselves, considered a means to an end (Georgakopoulos and Thomson, 2008, pp. 1120).

An arena structures and represents participants, patterns of interaction, communication and decision-making processes. Figure 1 shows the key elements of an arena. In the centre stage of the arena are pictured the main actors, namely those groups in society that intend to influence policies. Groups may be present in different arenas, if they focus on different issues. Each arena is characterised by formal codified rules coded and monitored by rule enforcers and informal rules that are learned and developed in the process of interactions between participants. Normally, these rules are external constraints for each participant. Formal rules may be laws, acts, and mandated procedures, while informal rules may be regulatory styles, political climate of group interactions, and role expectations. It may also happen that several participants join forces to change rules.

Rule enforcers ensure that participants abide by formal rules, on one hand, and may coordinate informal interactions and negotiations, on the other hand. Most rule enforcers are deemed to have powers delegated to them by political institutions via legislation (Georgakopoulos and Thomson, 2008, pp. 1121). In many arenas, the rule enforcers are also the ones that have the last word in decision-making. As a consequence, all actors try to communicate their claims to them and convince rule enforcers of their viewpoint, either by arguments or through public pressure.

Issue amplifiers play a similar role to "theatre critics", as they observe actions on stage, communicate with the participants, interpret their findings and report to the audience (Georgakopoulos and Thomson, 2008, pp. 1121). In this way, they influence the allocation of resources and the effectiveness of each resource to mobilize public support within the arena (Jaeger et al., 2001, pp. 177). Issue amplifiers can influence arena dynamics by mobilizing public support for particular factions within the arena. Their audience consists of other groups who may be enticed to enter the arena and individuals who may feel motivated to demonstrate their support or disagreement with participants.

\section{The arena concept applied in financial audit}

By using the arena concept in analyzing financial audit, stakeholders can be adequately differentiated and various interactions can be taken into consideration. The arena metaphor is in line with the typical traits of the audit profession, which has a rather unusual position compared to other traditional professions such as medicine and law. Financial auditors are highly respected experts whose work offers credibility to the financial statements audited by them and thus ensure trust in the market place. Their auditing process usually ends with an audit report, in which they state their opinion on the auditee's financial statements, whether these statements offer a true and fair view of the financial position and performance of the audited entity (Law no. 26/2010). Thus, the responsibility of the financial auditors is to report on the truthfulness of the financial statements, in a "quest for truth". They must ensure, of course, under the limits of their engagement, that the financial statements prepared by management reflect reality. 


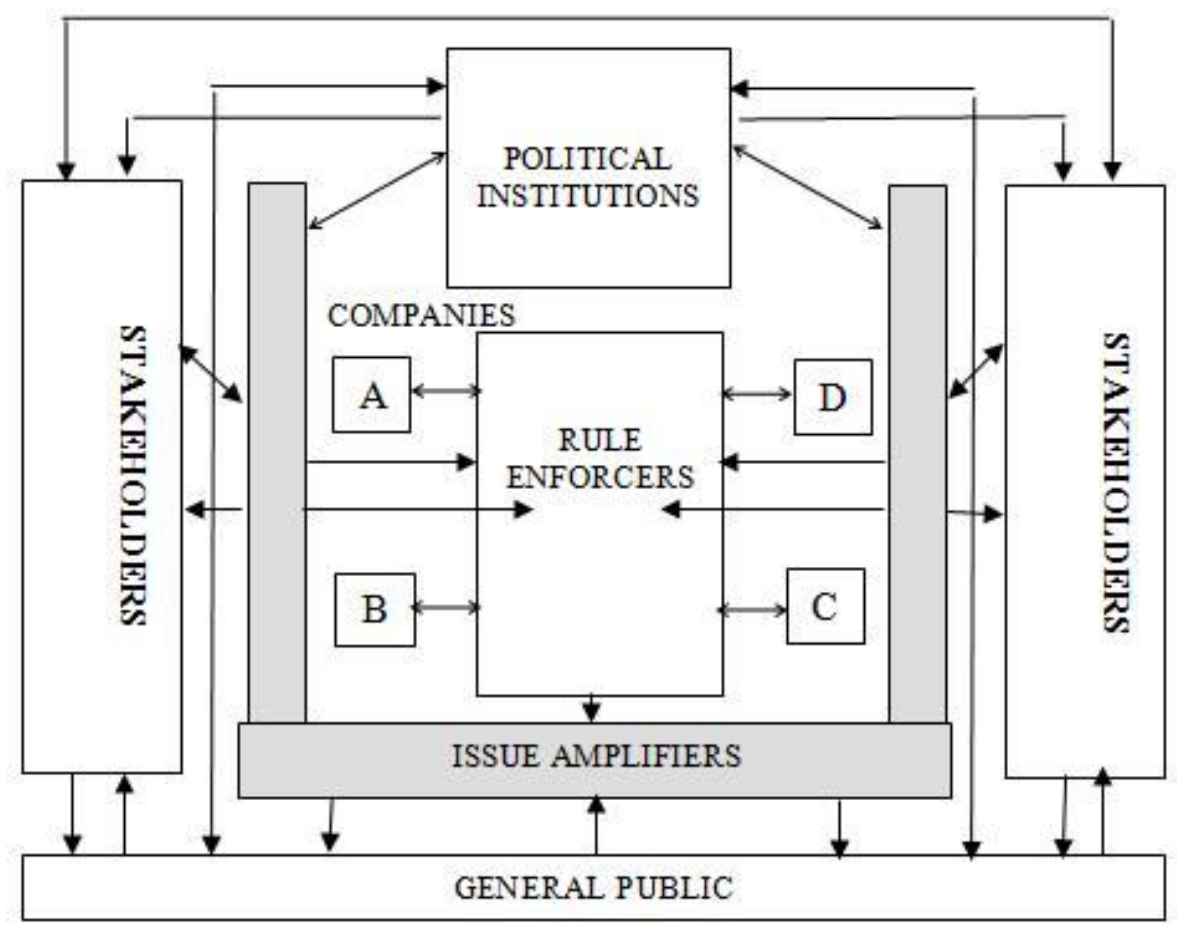

Figure no. 1: The Arena Concept

Source: Georgakopoulos and Thomson, 2008, pp. 1120

Generally, the systematic booking of the economic operations within an entity belongs to the accountants, while managers hold the end responsibility for preparing the financial statements (Order of the Public Finance Ministry no. 3055/2009). On this background, auditors certify that the financial statements prepared by accountants under the approval of management are trustworthy. Paradoxically, the direct beneficiaries of this auditing work are not the managers that also mandate and pay auditors for their services, but mainly the owners of the company and other third parties with a stake in the company. Unlike other professionals such as doctors, financial auditors may never come into contact with the persons whose interests they are supposed to represent. Another important aspect of auditing is that this profession is rather young compared to other traditional professions such as law and medicine. As a consequence, auditing lacks the history and the tradition of such professions. It grew rapidly, almost in the same pace as trade companies.

Therefore, these traits of the auditing profession (as presented by Cheffers and Pakaluk, 2007) reveal the need for an in-depth analysis of auditing by using the arena framework. First of all, auditors are responsible for a variety of stakeholders with whom they rarely come into contact, and these stakeholders and their objectives, as well as their power of influence should be properly identified. Their identification and the analysis of their interaction are enabled by the arena concept, which allows information to be placed in a context. Indeed, the analysis of the auditors and their work cannot be performed without a proper analysis of their environment, which is quite dynamic in the current economy.

Secondly, since the role of financial auditors is to provide trust in the market place, it is also critical that auditors are independent, objective, integer, competent and so on. But in order for these qualities of the auditors to be attained, the environment is also important. Auditors must face various pressures and influences from without, and the intensity and direction of these influences should be assessed, and perhaps modified, so that the auditor adequately fulfils its mission. Again, 
the use of the arena concept seems adequate. Thirdly, the auditing developed in a fast pace, simultaneously with the growth of trade companies, thus we find appropriate its analysis in connection with other participants at the economic environment.

The remainder of the paper aims at applying the arena concept in financial auditing by identifying the main actors, their objectives, their power, their amount of influence. The interaction among them is briefly analyzed, too, for the purpose of supporting the idea that strategic thinking is as important in financial audit as in other businesses/professions. Starting from figure 1, the following actors can be identified and analyzed, as shown below:

(1) Companies. In the context of the present study, the "companies" as actors in the arena include, on one hand, audit companies and, on the other hand, audited companies. These two categories belong to a broader class, that of "companies", which aim at financial prosperity and use resources for the purpose of adding value. Depending on their size and market share in the specific industry, they have more or less power in the arena. At present, the audit markets (both the international and the local markets) are dominated by the so-called "Big Four" companies, whose clients are also companies big in size, as these type of companies usually need an audit.

(2) Rule enforcers. Financial audit is a highly regulated profession. First of all, as members of a profession, financial auditors are part of a professional body, which ensures that all rules and regulations in force are observed. At present, at international level, there are International Auditing Standards in force, a Code of Ethics for Professional Accountants recently amended, as well as International Auditing Practice Statements and International Standards on Quality Control. Moreover, at the level of each country, there may be specific regulations on the work of financial auditors. Examples of rules enforcers are the International Auditing and Assurance Standards Board, or the European Council, at the level of the European Union, or the Financial Accounting Standards Board, in the United States of America. The objective of these organisms is to ensure an adequate legal framework for the functioning of auditing. Their influence is significant, since infringing the rules leads to disqualification as professional.

(3) Political institutions. Political institutions such as government, public finance ministry and other country-specific political institutions are also important actors in an arena. Their objectives may be various, starting with the general aim for a working economy and ending with the accurate collection of taxes from companies. Their influence is also significant in the arena.

(4) Stakeholders. Rubenstein (1986), cited by Porter (2009) classifies stakeholders from the perspective of the company's managers as follows: (1) Input stakeholders - employees, owners, suppliers and creditors; (2) Output stakeholders - consumers, distributors and users of the company's product or services; (3) Environment stakeholders - the community and local and central government. This classification can be also applied in financial audit. All these categories of stakeholders have an interest in the company and implicitly in the audit report. The most interested parties are the main beneficiaries of the audit work are the owners of the audited company, followed by other groups of stakeholders. Managers also have advantages from the auditing work, because they receive from auditors a letter with findings and recommendations, which support their future preparation of financial statements.

(5) Issue amplifiers. In case of financial audit, as in the case of other areas of activity, the issue amplifiers are represented by the media. Media is the one that puts under public debate all accounting scandals from the past years. Its influence is greater than initially thought, since as consequence of the immoral acts of professional accountants (auditors), the perception of the public and other stakeholders on the professionalism of auditors in general and in particular changed, leading even to change in rules.

(6) General public. The audience of the issue amplifiers is the general public, which may comprise simple citizens, in the position of consumers or employees. They are not directly influenced by auditors and their power, as individuals, is lower, however, they may be the "anonymous" voice that raises issues and changes things in the arena. 


\section{Discussion and conclusions}

The arena framework facilitates the understanding of financial audit. It is neither desirable nor realistic to determine the role of auditing and to analyze financial audit by means of a single audit report from a single auditor. On the contrary, the information that flows from different engagements is important in an arena, depending on what information is made available to other parties. This corresponds to reality, since decisions may usually be influenced, even slightly, by multiple parties of the audit environment (Georgakopoulos and Thomson, 2008, pp. 1121). Thus, the arena concept provides a skeletal frame and vocabulary that allows the reconstruction and representation of various engagements and interactions. However, the arena metaphor is not a predictive framework. On one hand, various actors may choose different strategies that interact with each other. The interactions of these strategies might even have an undesired outcome that does not comply with any of the actors' objectives. On the other hand, interactions in the arena may change the arena rules. Moreover, incremental changes in strategy or rules could lead to major changes in conflict outcomes. It is also difficult to predict the beneficiaries of potential rule changes driven by trial or error. These characteristics of the arena concept limit its use in predictions, but do not diminish its value in analyzing financial auditing (Jaeger et al., 2001, pp.178).

An important aspect revealed by the arena metaphor is that financial auditing takes place in a complex environment, with complex interactions. Although it is a profession that offers "noble" goods such as trust and credibility, financial auditing can also be seen as a business taking place in today's turbulent economic environment. From a business perspective, financial success is important to financial auditors, too. Here, relevant is the old question of "who shaves the barber?" Likewise, "who audits the auditor?"; "who ensures the going concern of an audit company?"; "who ensures its success?" As seen from the perspective of the arena concept applied in financial auditing, rule enforcers are rather powerful in the arena; however they are not the only actors with power and influence. The added-value of the arena concept consists in the fact that it provides a tool for analyzing the fight for power and influence in the auditing environment and is beneficial for a better understanding of the auditing activity at meso-level. Further research could aim, on one hand, at identifying a method by which levels of influence are measured and, on the other hand, at proposing a predictive analysis of the financial auditing arena.

\section{Acknowledgements}

This work was supported by CNCSIS -UEFISCSU, project number PNII - IDEI code ID_1015/2007, no. 360/01.10.2007, Actuality and perspective within the financial audit of the public entities.

This paper is also a result of the project POSDRU/6/1.5/S/11, Doctoral Program and PhD Students in the education research and innovation triangle”. This project is co funded by the European Social Fund through The Sectorial Operational Programme for Human Resources Development 2007-2013, coordinated by The Bucharest Academy of Economic Studies.

\section{References}

1. Carnegie G., Napier C. 2010. Traditional accountants and business professionals: Portraying the accounting profession after Enron, Accounting, Organizations and Society, 35 (3), pp. 360-376.

2. Cheffers M., Pakaluk M. 2007. Understanding Accounting Ethics, Allen David Press, Sutton;

3. Coate C. J., Florence R. E., Kral K. L. 2002. Financial Statement Audits, a Game of Chicken?, Journal of Business Ethics 41, 2002, pp. 1-11;

4. Cooper D., Neu D. 2006. Auditor and Audit Independence in an Age of Financial Scandals, in Professor Cheryl Lehman (ed.) Independent Accounts (Advances in Public Interest Accounting, Volume 12), Emerald Group Publishing Limited, pp. 1-15. 
5. Georgakopoulos, G., Thomson, I., 2008. Social reporting, engagements, controversies and conflict in an arena context. Accounting, Auditing \& Accountability Journal, 21 (8), pp. 1116-1143;

6. Humphrey C.; Loft A.; Woods M. 2009. The global audit profession and the international financial architecture: Understanding regulatory relationships at a time of financial crisis, Accounting, Organizations and Society, 34 (6-7), pp. 810-825.

7. International Federation of Accountants, Code of Ethics for Professional Accountants, 2010, available at http://web.ifac.org/publications;

8. Jaeger, C., Renn, O., Rosa, E. A., Webler, T., 2001. Risk, uncertainty, and rational action. London: Earthscan Publications; Law no. 26/2010 for amending the Emergency Ordinance no. $75 / 1999$ regarding the financial audit activity;

9. McMillan K. 2004. Trust and the virtues: a solution to the accounting scandals?, Critical Perspectives on Accounting, 15(6-7), pp. 943-953.

10. McPhail, K., Walters, D. 2009. Accounting \& Business Ethics: An Introduction, Routledge Taylor \& Frrancis Group, New York;

11. Nguyen, T., 2005. Jahresabschlussprüfung aus spieltheoretischer Sicht - Die Wirtschaftsprüfung, Heft 1-2, 2005, pp. 11-19;

12. Order of the Public Finance Ministry no. 3055/2009 for approving the Accounting regulations in accordance with the European Directives, published in the Official Gazette no. 766 of the $10^{\text {th }}$ of November 2009

13. Porter A. B. 2009. The audit trinity: the key to securing corporate accountability, Managerial Auditing Journal, Vol. 24 Nr. 2, pp. 156-182;

14. Sikka P. 2009. Financial crisis and the silence of the auditors, Accounting, Organizations and Society, 34(6-7), pp. 868-873.

15. Tucker R. R., Matsumura E. M., Subramanyam K.R. 2003. Going-concern judgments: An experimental test of the self-fulfilling prophecy and forecast accuracy, Journal of Accounting and Public Policy 22, 2003, pp. 401-432;

16. T,urlea E., Mocanu M. 2010. Strategic perspectives in financial audit, Financial Audit 6/2010, pp. 20-28; 